\title{
Clinical Study \\ The Incidence of Hypogonadotropic Hypogonadism in Type 2 Diabetic Men in Polish Population
}

\author{
Michał Rabijewski, ${ }^{1}$ Lucyna Papierska, ${ }^{2}$ Wojciech Zgliczyński, ${ }^{2}$ and Pawel Piątkiewicz \\ ${ }^{1}$ Department of Internal Diseases, Diabetology and Endocrinology, Warsaw Medical University, Kondratowicza Street 8, \\ 03-242 Warsaw, Poland \\ ${ }^{2}$ Department of Endocrinology, Medical Centre for Postgraduate Education, Warsaw, Poland
}

Correspondence should be addressed to Michał Rabijewski; mirab@cmkp.edu.pl

Received 30 April 2013; Revised 27 August 2013; Accepted 16 September 2013

Academic Editor: Gabriel F. Anhe

\begin{abstract}
Copyright (C) 2013 Michał Rabijewski et al. This is an open access article distributed under the Creative Commons Attribution License, which permits unrestricted use, distribution, and reproduction in any medium, provided the original work is properly cited.

The aim of this study was to investigate the incidence of hypogonadotropic hypogonadism (HH) in type 2 diabetic men (T2DM) in population of Polish men and examine the possible influence of estradiol levels and glycemic control. We evaluated TT, cfT, estradiol, and glycemic control (HbAlc) in 184 diabetic men and in 149 nondiabetic control group. The mean HbAlc was $8.6 \pm$ $0.2 \%$ and $6.1 \pm 0.3 \%$ and cfT concentration was $0.315 \pm 0.08 \mathrm{nmol} / \mathrm{L}$ and $0.382 \pm 0.07 \mathrm{nmol} / \mathrm{L}$, respectively. T2DM had higher E2 concentration than nonobese control men $(29.4 \pm 3.7 \mathrm{pg} / \mathrm{mL}$ versus $24.5 \pm 2.9 \mathrm{pg} / \mathrm{mL})$. Forty-six percent of T2DM were hypogonadal and 93\% had HH. We observed inverse relationship between BMI and $\mathrm{cfT}(r=-0.341, P<0.01)$ and positive between BMI and E2 $(r=0.329, P<0.01)$. E2 concentration was higher in T2DM with HH versus T2DM with normal TT/cfT concentration (34.5 \pm 5.2 versus $27.4 \pm 3.4 \mathrm{pg} / \mathrm{mL})$. We observed negative correlation between HbAlc and $\mathrm{cfT}(r=-0.336, P<0.005)$ but positive between HbAlc and E2 levels $(r=0.337, P<0.002)$. The prevalence of obesity, hypertension, and CVD was higher in men with hypogonadism. High incidence of hypogonadotropic hypogonadism in type 2 diabetic men in Polish population is associated with poor glycemic control and can be secondary to an increase in estradiol concentrations.
\end{abstract}

\section{Introduction}

The prevalence of diabetes mellitus is rapidly increasing. By the year 2030, there are expected to be almost twice as many older persons with diabetes in developing countries compared to the more developed ones [1]. Incidence of diabetes in Poland is higher than observed in Western European countries. In the general Polish population aged 20-74 years diabetes was diagnosed in $6.8 \%$ individuals, including $7.4 \%$ men and $6.2 \%$ women. Incidence of diabetes increases with age: in men from $0.7 \%$ in those aged $20-29$ years to $16.3 \%$ in those aged $>60$ years [2]. In Polish-Norwegian Study (PONS) performed among people aged 45-64 diabetes was diagnosed in $12.2 \%$ males and $6.4 \%$ females [3].

Type 2 diabetes in men is associated with lower total testosterone (TT) and free testosterone (fT) levels in crosssectional studies, and the majority of these men have signs and symptoms of hypogonadism such as erectile dysfunctions
(ED), low libido, fatigue, sarcopenia, and depression [4]. The origin of these findings is complex, but about $25-40 \%$ type 2 diabetic men (T2DM) have low testosterone concentrations in association with inappropriately low or normal LH and FSH concentrations and diagnosis of hypogonadotropic hypogonadism $(\mathrm{HH})$ can be established. About $4 \%$ of T2DM have subnormal testosterone concentrations with elevated LH and FSH concentrations, which can be associated with primary testis dysfunctions [4].

The possible pathophysiological mechanisms underlying $\mathrm{HH}$ in T2DM are still unknown. Low testosterone levels in men are associated with insulin resistance and reduced insulin sensitivity [5]. Moreover, low testosterone levels have also been found to predict insulin resistance and the future development of type 2 diabetes [6]. In study of a large number of obese men (mean age 60 years) 44\% of T2DM and 33\% of age-matched nondiabetic men had subnormal testosterone concentrations [7]. Testosterone levels are inversely related 
to body mass index (BMI), but the testosterone deficiency in T2DM was not dependent upon obesity, because $25 \%$ of nonobese patients also had $\mathrm{HH}[8]$.

$\mathrm{HH}$ is relatively rare in type 1 diabetes and therefore is not a function of diabetes or hyperglycemia itself [9]. Thus, in view of the inverse relationship between BMI and testosterone concentrations in both type 1 and type 2 diabetes, $\mathrm{HH}$ is probably related to insulin resistance $[4,5]$. Testosterone can be converted to estradiol in the adipose tissue, and it has been suggested that excessive estrogen secretion in the obese may suppress secretion of GnRH and LH [10]. However, in recent studies estradiol levels in men with $\mathrm{HH}$ were significantly lower than in those without $\mathrm{HH}$ [11].

Low testosterone concentration in T2DM is associated with two to three times elevated risk of cardiovascular events and death [12]; therefore, serum testosterone should be measured in men with type 2 diabetes mellitus with symptoms suggestive of testosterone deficiency [13].

The high prevalence of diabetes mellitus in population of Polish men is well documented, but the prevalence of $\mathrm{HH}$ in T2DM is now unknown. In our earlier study we showed that in a cohort of Polish men with poor health status the prevalence of testosterone deficiency in elderly men with ED is higher than in other countries [14]. So, we hypothesize that the incidence of $\mathrm{HH}$ in T2DM also can be higher than in other studies and is associated with late identification of patients with type 2 diabetes and improper glycemic control.

Therefore, the aim of this study was to investigate the incidence of hypogonadotropic hypogonadism in T2DM in Polish population and examine the possible influence of estradiol levels and glycemic control.

\section{Material and Methods}

This was a cross-sectional study of 184 type 2 diabetic men, aged $>45$ years (age range $47-63$ years), who were registered with the Department of Endocrinology, Medical Centre of Postgraduate Education, Warsaw, Poland. All patients gave written informed consent, and the local research ethics committee approved the protocol (CMKP/501-2-1-07-21/2009).

Patients with known history of hypogonadism, panhypopituitarism, chronic debilitating disease, or were already receiving hormone replacement therapy were excluded from the study. Demographic parameters, clinical history including the duration of diabetes, medications, and the presence of erectile dysfunction and coronary artery disease were collected, and height, weight, fasting glucose, and HbAlc were measured. Type 2 diabetes was diagnosed according to WHO criteria [15]. Nine patients were treated with diet alone, 77 with insulin, and 98 with oral hypoglycemic agents. Height and weight were measured, and BMI was calculated. Cardiovascular disease was defined as self-reported coronary artery disease, cerebrovascular disease, congestive heart failure, or arrhythmia.

Fasting blood samples were then obtained between 8:00 and 10:00 A.M. to measure serum total testosterone (TT), estradiol (E2), sex hormone binding globuline (SHBG), luteinizing hormone (LH), follicle-stimulating hormone (FSH), prolactin (PRL), fasting plasma glucose (FPG), and HbAlc. All men had their total testosterone (TT), LH, FSH, and PRL levels checked at least once. TT, LH, FSH, and PRL were measured by chemiluminescent immunometric assays (Immulite 2000; DPC USA and Coat-a-Coat; Siemens USA). The normal value for testosterone was $8-28 \mathrm{nmol} / \mathrm{L}$ (sensitivity-4 ng/dL), for LH: $2-6 \mathrm{mIU} / \mathrm{L}$ (sensitivity$0.05 \mathrm{mIU} / \mathrm{L}$ ), for FSH: 3-10 mIU/L (sensitivity-0.1 mIU/L), and for PRL: $12-24 \mathrm{ng} / \mathrm{mL}$ (sensitivity-0.16 ng/mL). Calculated free testosterone (cFT) was calculated from SHBG, serum albumin, and TT using the method of Vermeulen and colleagues [16]. A free testosterone level $<0.255 \mathrm{nmol} / \mathrm{L}$ was taken as low. TT concentration $<8 \mathrm{nmol} / \mathrm{L}$ was considered to be low, and between 8 and $12 \mathrm{nmol} / \mathrm{L}$ was considered to be borderline low. $\mathrm{HH}$ was defined as TT levels $<12 \mathrm{nmol} / \mathrm{L}$ $\mathrm{LH}$ levels $<6 \mathrm{mIU} / \mathrm{mL}$, and FSH levels $<8 \mathrm{mIU} / \mathrm{mL}$. Primary hypogonadism was defined as TT levels $<12 \mathrm{nmol} / \mathrm{L}, \mathrm{LH}$ levels $>6 \mathrm{mIU} / \mathrm{mL}$, and $\mathrm{FSH}$ levels $>8 \mathrm{mIU} / \mathrm{mL}$.

Sexual function was assessed according to the International Index of Erectile Function (IIEF-5) questionnaire. Possible scores on the IIEF-5 are 1 to 25 and erectile dysfunction was classified into 5 categories based on the scores, namely, severe -1 to 7 , moderate -8 to 11 , mild to moderate -12 to 16 , mild -17 to 21 and none- 22 to 25 .

Statistical analysis was performed using statistica software. Data are presented as mean \pm SE. Mann Whitney rank sum test was used to compare nonparametric data, and Student's $t$ test was used to compare parametric data. Spearman correlation (for nonparametric data) or Pearson correlation (for parametric data) was used to establish correlations. All relationships were assessed by linear univariate and multivariate regression analysis to reduce bias in a cross-sectional study. Results were considered statistically significant at $P<0.05$.

\section{Results}

A total of 184 T2DM and 149 nondiabetic control men were evaluated in the study. Characteristics of all T2DM men, patients with $\mathrm{HH}$, primary hypogonadism, normal testosterone concentration, and nonobese control group are shown in Table 1 . The mean age in T2DM group and nonobese control group was $58.5 \pm 2.3$ years and $59.6 \pm 3.2$ years; mean body mass index (BMI) was $31.4 \pm 0.5 \mathrm{~kg} / \mathrm{m}^{2}$ and $27.6 \pm$ $1.2 \mathrm{~kg} / \mathrm{m}^{2}$, and mean HbAlc was $8.6 \pm 0.2 \%$ and $6.1 \pm$ $0.3 \%$, respectively. The mean TT concentration was $13.3 \pm$ $1.65 \mathrm{nmol} / \mathrm{L}$ and $17.1 \pm 1.7 \mathrm{nmol} / \mathrm{L}$, and $\mathrm{cfT}$ concentration was $0.315 \pm 0.08 \mathrm{nmol} / \mathrm{L}$ and $0.382 \pm 0.07 \mathrm{nmol} / \mathrm{L}$. We observed statistically higher E2 concentration in T2DM group than in nonobese control men $(29.4 \pm 3.7 \mathrm{pg} / \mathrm{mL}$ and $24.5 \pm$ $2.9 \mathrm{pg} / \mathrm{mL}, P<0.001)$.

Thus, we showed that TT and cf T concentrations in all T2DM group were statistically significantly lower than in nondiabetic control group with the same average age (Table 1). Forty-six percent of T2DM $(n=86)$ were hypogonadal, and in 82 of these patients (93\%) LH and FSH levels were significantly lower when compared with patients 
TABLE 1: Characteristics of all T2DM, patients with HH, primary hypogonadism (PH), and with normal testosterone concentration (normal $\mathrm{TT} / \mathrm{cfT}$ ) and nondiabetic control men.

\begin{tabular}{|c|c|c|c|c|c|c|c|}
\hline Parameter & T2DM with $\mathrm{HH}$ & T2DM with $\mathrm{PH}$ & $\begin{array}{c}\text { T2DM with } \\
\text { normal TT/cfT }\end{array}$ & All T2DM & $P^{*}$ & $\begin{array}{l}\text { Nondiabetic } \\
\text { control group }\end{array}$ & $P^{* *}$ \\
\hline Number of patients & 82 & 5 & 99 & 184 & & 149 & \\
\hline Age (years) & $56.4 \pm 3.2$ & $5.4 \pm 3.1$ & $57.6 \pm 2.7$ & $58.5 \pm 2.3$ & NS & $59.6 \pm 3.2$ & NS \\
\hline $\mathrm{TT}(\mathrm{mmol} / \mathrm{L})$ & $10.3 \pm 1.2$ & $11.1 \pm 1.3$ & $16.4 \pm 1.95$ & $13.3 \pm 1.65$ & 0.002 & $17.1 \pm 1.7$ & 0.001 \\
\hline $\mathrm{cfT}(\mathrm{nmol} / \mathrm{L})$ & $0.225 \pm 0.05$ & $0.287 \pm 0.06$ & $0.375 \pm 0.05$ & $0.315 \pm 0.08$ & 0.002 & $0.382 \pm 0.07$ & 0.01 \\
\hline SHBG (nmol/L) & $31.3 \pm 2.1$ & $30.3 \pm 2.6$ & $29.7 \pm 2.3$ & $30.9 \pm 1.98$ & 0.05 & $28.7 \pm 2.04$ & 0.05 \\
\hline LH (mIU/L) & $3.5 \pm 0.3$ & $10.3 \pm 1.2$ & $7.3 \pm 0.3$ & $6.5 \pm 0.2$ & 0.02 & $7.6 \pm 0.3$ & 0.02 \\
\hline FSH (mIU/L) & $5.8 \pm 0.6$ & $13.4 \pm 1.8$ & $9.2 \pm 0.45$ & $8.8 \pm 0.3$ & 0.02 & $8.6 \pm 0.8$ & NS \\
\hline Estradiol (pg/mL) & $34.5 \pm 3.1$ & $32.5 \pm 3.7$ & $27.4 \pm 3.4$ & $29.4 \pm 3.7$ & 0.002 & $24.5 \pm 2.9$ & 0.001 \\
\hline BMI $\left(\mathrm{kg} / \mathrm{m}^{2}\right)$ & $32.4 \pm 1.4$ & $31.1 \pm 2.2$ & $30.6 \pm 1.3$ & $31.4 \pm 0.9$ & 0.05 & $27.6 \pm 1.2$ & 0.02 \\
\hline HbAlc (\%) & $8.9 \pm 1.4$ & $8.8 \pm 1.3$ & $8.4 \pm 1.2$ & $8.6 \pm 1.3$ & 0.002 & $6.1 \pm 0.3$ & 0.002 \\
\hline $\mathrm{FPG}(\mathrm{mmol} / \mathrm{L})$ & $8.3 \pm 0.7$ & $8.2 \pm 0.6$ & $7.6 \pm 0.5$ & $7.9 \pm 0.7$ & 0.05 & $5.3 \pm 0.4$ & 0.001 \\
\hline
\end{tabular}

${ }^{*} P$ shows differences between patients with $\mathrm{HH}$ and with normal testosterone levels.

${ }^{*} * P$ shows differences between TD2M and nonobese control group.

Pearson coefficient of BMI and TT: $r=-0.362 ; P<0.01$ in all T2DM group.

Pearson coefficient of BMI and cfT: $r=-0.341, P<0.01$ in all T2DM group.

Pearson coefficient of BMI and E2: $r=0.329 ; P<0.01$ in all T2DM group.

Pearson coefficient of HbAlc and TT: $r=-0.346, P<0.002$ in all T2DM group.

Pearson coefficient of HbAlc and cfT: $r=-0.336 ; P<0.005$ in all T2DM group.

Pearson coefficient of HbAlc and E2: $r=0.337 ; P<0.002$ in all T2DM group.

Pearson coefficient of FPG and TT: $r=-0.345, P<0.002$ in all T2DM group.

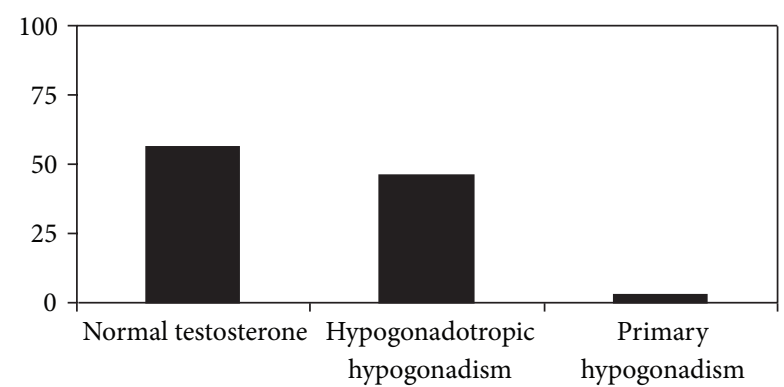

Figure 1: The incidence percentage of normal testosterone levels compared with patients with $\mathrm{HH}$ and primary hypogonadism in T2DM in Polish population.

with normal TT/cfT levels $(3.5 \pm 0.3$ versus $7.3 \pm 0.3 \mathrm{mIU} / \mathrm{mL}$ for $\mathrm{LH}$ and $5.8 \pm 0.6$ versus $9.2 \pm 0.45 \mathrm{mIU} / \mathrm{mL}$ for $\mathrm{FSH}$; $P<0.02$ ), and only 4 men had testosterone, LH, and FSH concentrations characteristic to primary hypogonadism. Figure 1 shows the percentage of patients with normal TT/cfT levels and patients with $\mathrm{HH}$ and primary hypogonadism.

Pearson coefficients of BMI and TT concentration showed a statistically significant inverse relationship $(r=$ $-0.362 ; P<0.01)$. Also inverse relationship between BMI and cfT concentration $(r=-0.341, P<0.01)$ was observed. There was also positive correlation between BMI and E2 $(r=0.329 ; P<0.01)$. SHBG correlated inversely with BMI $(r=-0.277 ; P<0.05)$ but positively with age $(r=$ $0.538 ; P<0.001)$ and TT $(r=0.543 ; P<0.001)$. E2 concentration was significant higher in T2DM with $\mathrm{HH}$ versus T2DM with normal TT/cfT concentration $(34.5 \pm 5.2$ versus $27.4 \pm 3.4 \mathrm{pg} / \mathrm{mL}$, resp.), but we did not observed statistical significant differences between T2DM with normal TT/cfT concentration and nonobese control men (27.4 \pm 3.4 versus $28.2 \pm 3.2 \mathrm{pg} / \mathrm{mL}$, resp.). These results were significant after adjustment for BMI and age.

We observed statistically significant negative correlation between HbAlc and TT and between FPG and TT concentrations $(r=-0.346, P<0.002$ and $r=-0.345, P<0.002$, resp.) and significant negative correlation between HbAlc and cfT concentrations $(r=-0.336 ; P<0.005)$ but there was no correlation between FPG and cf T concentrations. There was also positive correlation between $\mathrm{HbAlc}$ and BMI and between HbAlc and E2 levels $(r=0.382, P<0.02$ and $r=0.337 ; P<0.002$, resp.). After adjusting for age, TT/E2 ratio was negatively associated with $\mathrm{BMI}(P<0.001)$.

Multivariate linear regression analysis showed that obesity negatively correlated with TT levels with a mean decrease of $25 \mathrm{ng} / \mathrm{dL}$ per $1 \mathrm{~kg} / \mathrm{m}^{2}$ increase in BMI score $(P<0.005)$. Also, age negatively correlated with TT and cfT levels with a mean decrease of $1.8 \mathrm{ng} / \mathrm{dL}$ and $0.003 \mathrm{nmol} / \mathrm{L}$ for each year of additional age over 45 years old, respectively $(P<0.002)$.

The degree of erectile dysfunction in all T2DM group was mild in $24 \%$ of cases, mild to moderate in $31.5 \%$, moderate in $24.5 \%$, and severe in $20 \%$ (Table 2 ), and there were significant differences between patients with normal TT/cfT concentrations and patients with hypogonadism $(P<$ 0.02). IIEF-5 score and TT showed a statistically inverse relationship $(r=-0.3149, P<0.05)$.

In Table 3, we presented prevalence of tobacco use, hypertension, dyslipidemia, obesity, and cardiovascular disease (CVD) in all T2DM. The prevalence of each condition, except tobacco use, was above $60 \%$ and prevalence of obesity, 
TABLE 2: Degree of erectile dysfunction (number of patients; percentage) according to IIEF-5 scale in all T2DM, patients with HH and with normal TT/cfT.

\begin{tabular}{lccc}
\hline IIEF-5 & Men with HH $(n=82)$ & Normal TT/cfT $(n=99)$ & All men $(n=184)$ \\
\hline Mild & $16(19)$ & $29(29)$ & $44(24)$ \\
Mild to moderate & $28(34)$ & $29(29)$ & $58(31.5)$ \\
Moderate & $18(22.5)$ & $22(23)$ & $45(24.5)$ \\
Severe & $20(24.5)$ & $19(19)$ & $37(20)$ \\
\hline
\end{tabular}

Significant differences between patients with normal testosterone concentration and patients with hypogonadism $(P<0.02)$.

Variables of IIEF-5 score and TT: $r=-0.3149, P<0.05$.

TABLE 3: Clinical characteristics (number of patients; percentage) of all T2DM, patients with $\mathrm{HH}$ and with normal TT/cfT concentration.

\begin{tabular}{|c|c|c|c|c|}
\hline Parameter & Men with $\mathrm{HH}(n=82)$ & Normal TT/cfT $(n=99)$ & All men $(n=184)$ & $P$ value \\
\hline Obesity & $79(96)$ & $72(73)$ & $151(82)$ & 0.002 \\
\hline Current smoker & $62(76)$ & $75(76)$ & $137(75)$ & NS \\
\hline Hypertension & $65(79)$ & $62(62)$ & 127 (69) & 0.005 \\
\hline Dyslipidemia & $61(74)$ & $65(65)$ & $126(69)$ & 0.02 \\
\hline CVD & $57(70)$ & $61(61)$ & $118(64)$ & 0.05 \\
\hline
\end{tabular}

$P$ value shows significant differences between patients with normal testosterone concentration and patients with hypogonadism.

CVD: cardiovascular disease.

hypertension, and CVD was significantly higher in men with hypogonadism compared with eugonadal patients. The most common metabolic disorders were obesity (79\% in men with hypogonadism and $93 \%$ in men with normal TT/cfT levels) and hyperlipidemia (51\% and $93 \%$, resp.).

\section{Discussion}

We evaluated the incidence of $\mathrm{HH}$ in Polish population of 184 T2DM. It was the first study performed in the relative large population of men in Poland. To our knowledge, this is the first report showing such high incidence of $\mathrm{HH}$ in population of T2DM with poor health status. In our cohort $46 \%$ patients were hypogonadal and $93 \%$ of these patients covered criteria for recognizing of $\mathrm{HH}$.

Dhindsa et al. [8] described the association of $\mathrm{HH}$ with type 2 diabetes in 103 T2DM in mean age 54.7 years. Authors revealed that $33 \%$ of studied T2DM were hypogonadal, and $\mathrm{LH}$ and FSH levels were significantly lower in the hypogonadal group compared with patients with normal testosterone levels. In study of Rhoden et al. [17] in 116 diabetic men TT serum levels were subnormal in $34 \%$ of patients, and TT levels were strongly associated with elevated BMI. Corona et al. [18] in an investigation of 1200 patients with ED (16\% with type 2 diabetes) observed $\mathrm{HH}$ in $24.5 \%$ diabetic men versus $12.6 \%$ in the rest of the group. Differences in the prevalence of hypogonadism retained significance after adjustment for age and BMI. In cross-sectional study of 355 type 2 diabetic men aged $>30$ years Kapoor et al. [19] observed low testosterone levels in diabetic men, and a significant proportion of these men had symptoms of hypogonadism. In a cross-sectional survey of 580 men with type 2 diabetes Laaksonen et al. [20] found that $43 \%$ of men with type 2 diabetes had a reduced TT concentration, and low testosterone levels were independently associated with insulin resistance.
The incidence of hypogonadism among patients with type 2 diabetes was significantly greater in our study than observed in studies cited above. Hypogonadism can be associated with diabetes per se, but vascular factors, drugs, tobacco, alcohol, and systemic diseases such as hypertension, heart diseases, and dyslipidemia can be risk factors of testosterone deficiency. In our study we observed high prevalence of tobacco use, hypertension, dyslipidemia, cardiovascular disease, and obesity (over 60\% for each condition). Very high prevalence of these diseases, higher than in cited studies, can be one of the explanation of differences in incidence of hypogonadism between population of Polish men and patients in Western Europe countries and the United States. In our earlier publication we showed [14] that late-onset hypogonadism $(\mathrm{LOH})$ was very common in population of Polish men presenting ED and correlated negatively with age, obesity, and dyslipidemia. These results can also be associated with poor health status of Polish population, like in this study.

In patients with type 2 diabetes hypogonadism is secondary in origin (hypogonadotropic), but possible pathophysiological mechanisms underlying $\mathrm{HH}$ in these patients remain partly unexplained. Testosterone in the male can be converted through the action of aromatase to estradiol (E2) and estrone (E1) in the mesenchymal cells, preadipocytes, and adipocytes of adipose tissue. Because obesity is closely connected with diabetes and aging, it has been suggested that excessive E2 secretion due to high aromatase activity in the obese patients may suppress testosterone synthesis as a result of suppression of the hypothalamic secretion of GnRH [10]. But in previous study this hypothesis was not confirmed. In European male aging study estradiol levels in hypogonadal men were significantly lower than in eugonadal men [11], but only few percent of these men were diabetic. In population of T2DM with normal weight Dhindsa et al. observed no association of $\mathrm{HH}$ with elevated E2 concentration [8]. Although in all cited studies above 
testosterone concentrations were inversely related to BMI but low testosterone concentration was not closely depended upon high BMI. In our study, we also observed statistically significant inverse relationship between TT, cfT, and BMI as well as positive correlation between BMI and E2; however, T2DM with $\mathrm{HH}$ had significantly higher E2 concentration and lower TT/E2 ratio than eugonadal T2DM. These observations can be in part associated with very high prevalence of obesity in our population (96\%) and higher BMI than in other studies (mean BMI $32.4 \mathrm{~kg} / \mathrm{m}^{2}$ ). However, Mogri et al. [21] in population of obesity pubertal and postpubertal males showed that obese males had significantly lower TT and cf T concentrations as compared to lean males, but fT concentrations were positively related to age. Interestingly, total and free estradiol levels were significantly lower in males with subnormal testosterone concentrations. So, in this study obesity in young males was associated with low testosterone concentrations, which were not secondary to an increase in estradiol concentrations. In our study we measured total but not free or bioavailable estradiol concentration, while these fractions of estradiol in other studies were directly related to testosterone concentrations in T2DM.

In previous study, the prevalence of hypogonadism was not dependent on severity of hyperglycemia assessed as glycosylated hemoglobin (HbAlc) levels [1-8, 8-19]. We observed significant negative correlation between $\mathrm{HbAlc}$ and testosterone concentration; thus, in population of Polish T2DM severity of hyperglycemia probably can influence the incidence of $\mathrm{HH}$. These findings can also be associated with relative late identification of diabetic patients in our country (mean HbAlc level in all group was $8.4 \%$ and in $\mathrm{HH}$ patients-8.9\%).

Hypogonadism in men is associated with insulin resistance [5], visceral obesity, the risk of metabolic syndrome [22, 23], vascular complications of diabetes [24], and risk for developing type 2 diabetes $[6,24]$. Also in nondiabetic men testosterone levels were inversely associated with insulin levels and HOMA [25]. These observations confirmed the hypothesis that testosterone levels in diabetic men may be influenced by insulin resistance (a key feature of type 2 diabetes) and may play an important role in pathogenesis of $\mathrm{HH}$.

In mice selective deletion of the insulin receptors from neurons leads to a reduction in LH and FSH levels by 60$90 \%$; testosterone deficiency and disruption of spermatogenesis while incubation of hypothalamic neurons with insulin solution result in the reinforcement of secretion of $\mathrm{GnRH}[26$, 27]. In male mice with deletion of the androgen receptors, increased glucose levels and insulin resistance were observed [28]. Moreover, visceral adiposity is associated with insulin resistance and hypogonadism as a result of testosterone conversion to estradiol $[29,30]$. In our study, we observed correlation between testosterone and BMI similar to other studies [18-20]. Thus, appropriate insulin action in the hypothalamo-hypophyseal neurons is crucial in stimulation of testosterone synthesis and spermatogenesis.

Erectile dysfunctions are an important problem in patients with diabetes but also with hypogonadism [18].
We observed significant differences in the degree of erectile dysfunction according to IIEF-5 score between eugonadal patients and men with hypogonadism. Moreover, IIEF-5 score and TT concentrations showed a statistically inverse relationship.

In the absence of modifiable etiology of hypogonadism and contraindications to treatment, testosterone replacement therapy may be taken into account [13, 30]. Short-term studies in men have shown that testosterone supplementation may improve insulin sensitivity [31-33], but the balance of benefits and risks is still unknown.

A couple of the issues affecting its accuracy can be cited as weaknesses in our data set. First of all our model in no way established a causal link between hypogonadism and type 2 diabetes, because the two conditions might simply overlap and they may have probably separate pathophysiologic pathways.

In Polish population hypogonadism is closely connected with type 2 diabetes and routine testosterone screening should be performed in all T2DM. Our study results strongly justify this practice. The Endocrine Society and the International Society for the Study of the Aging Male (ISSAM) now recommend the measurement of testosterone in patients with type 2 diabetes as a routine basis $[13,30]$, but this practice is not common and widely accepted in Poland.

In conclusion, we observed high incidence of hypogonadotropic hypogonadism in type 2 diabetic men in Polish population which is associated with poor glycemic control and can be secondary to an increase in estradiol concentrations.

\section{Conflict of Interests}

The authors report no conflict of interests.

\section{Acknowledgments}

This study was supported by research Grant no. 501-2-107-21/09 of the Medical Centre of Postgraduate Education, Poland.

\section{References}

[1] M. J. Kim, Y. Rolland, O. Cepeda, J. K. Gammack, and J. E. Morley, "Diabetes mellitus in older men," The Aging Male, vol. 9, no. 3, pp. 139-147, 2006.

[2] M. Polakowska and W. Piotrowski, "Incidence of diabetes in the Polish population: results of the multicenter Polish population health status study-WOBASZ," Polskie Archiwum Medycyny Wewnetrznej, vol. 121, no. 5, pp. 156-163, 2011.

[3] K. Zatońska, R. Ilow, B. Regulska-Ilow et al., "Prevalence of diabetes mellitus and IFG in the prospective cohort 'PONS' studybaseline assessment," Annals of Agricultural and Environmental Medicine, vol. 18, no. 2, pp. 265-269, 2011.

[4] P. Dandona and S. Dhindsa, "Update: hypogonadotropic hypogonadism in type 2 diabetes and obesity," Journal of Clinical Endocrinology and Metabolism, vol. 96, no. 9, pp. 2643-2651, 2011. 
[5] M. Grossmann, M. C. Thomas, S. Panagiotopoulos et al., "Low testosterone levels are common and associated with insulin resistance in men with diabetes," Journal of Clinical Endocrinology and Metabolism, vol. 93, no. 5, pp. 1834-1840, 2008.

[6] E. Selvin, M. Feinleib, L. Zhang et al., "Androgens and diabetes in men: Results from the Third National Health and Nutrition Examination Survey (NHANES III)," Diabetes Care, vol. 30, no. 6, pp. 234-238, 2007.

[7] S. Dhindsa, M. G. Miller, C. L. McWhirter et al., "Testosterone concentrations in diabetic and nondiabetic obese men," Diabetes Care, vol. 33, pp. 1186-1192, 2010.

[8] S. Dhindsa, S. Prabhakar, M. Sethi, A. Bandyopadhyay, A. Chaudhuri, and P. Dandona, "Frequent occurrence of hypogonadotropic hypogonadism in type 2 diabetes," Journal of Clinical Endocrinology and Metabolism, vol. 89, no. 11, pp. 5462-5468, 2004.

[9] R. Tomar, S. Dhindsa, A. Chaudhuri, P. Mohanty, R. Garg, and P. Dandona, "Contrasting testosterone concentrations in type 1 and type 2 diabetes," Diabetes Care, vol. 29, no. 5, pp. 1120-1122, 2006.

[10] N. Pitteloud, A. A. Dwyer, S. DeCruz et al., "The relative role of gonadal sex steroids and gonadotropin-releasing hormone pulse frequency in the regulation of follicle-stimulating hormone secretion in men," Journal of Clinical Endocrinology and Metabolism, vol. 93, no. 7, pp. 2686-2692, 2008.

[11] A. Tajar, G. Forti, T. W. O’Neill et al., "Characteristics of secondary, primary, and compensated hypogonadism in aging men: evidence from the European male ageing study," Journal of Clinical Endocrinology and Metabolism, vol. 95, no. 4, pp. 18101818, 2010.

[12] G. A. Laughlin, E. Barrett-Connor, and J. Bergstrom, "Low serum testosterone and mortality in older men," Journal of Clinical Endocrinology and Metabolism, vol. 93, no. 1, pp. 68-75, 2008.

[13] C. Wang, E. Nieschlag, R. Swerdloff et al., "ISA, ISSAM, EAU, EAA and ASA recommendations: investigation, treatment and monitoring of late-onset hypogonadism in males," International Journal of Impotence Research, vol. 21, no. 1, pp. 1-8, 2009.

[14] M. Rabijewski, L. Papierska, J. Kozakowski et al., "The high prevalence of testosterone deficiency in population of Polish men over 65 years with erectile dysfunctions," The Aging Male, vol. 15, pp. 258-262, 2012.

[15] American Diabetes Association, "Diagnosis and classification of diabetes mellitus," Diabetes Care, vol. 35, supplement 1, pp. $1-8,2012$.

[16] A. Vermeulen, L. Verdonck, and J. M. Kaufman, "A critical evaluation of simple methods for the estimation of free testosterone in serum," Journal of Clinical Endocrinology and Metabolism, vol. 84, no. 10, pp. 3666-3672, 1999.

[17] E. L. Rhoden, E. P. Ribeiro, C. Teloken, and C. A. V. Souto, "Diabetes mellitus is associated with subnormal serum levels of free testosterone in men," BJU International, vol. 96, no. 6, pp. 867-870, 2005.

[18] G. Corona, E. Mannucci, L. Petrone et al., "Association of hypogonadism and type II diabetes in men attending an outpatient erectile dysfunction clinic," International Journal of Impotence Research, vol. 18, no. 2, pp. 190-197, 2006.

[19] D. Kapoor, H. Aldred, S. Clark, K. S. Channer, and T. H. Jones, "Clinical and biochemical assessment of hypogonadism in men with type 2 diabetes: correlations with bioavailable testosterone and visceral adiposity," Diabetes Care, vol. 30, no. 4, pp. 911-917, 2007.

[20] D. E. Laaksonen, L. Niskanen, K. Punnonen et al., “Testosterone and sex hormone-binding globulin predict the metabolic syndrome and diabetes in middle-aged men," Diabetes Care, vol. 27, no. 5, pp. 1036-1041, 2004.

[21] M. Mogri, S. Dhindsa, T. Quattrin et al., "Testosterone concentrations in young pubertal and post-pubertal obese males," Clinical Endocrinology, vol. 78, no. 4, pp. 593-599, 2013.

[22] D. E. Laaksonen, L. Niskanen, K. Punnonen et al., "Sex hormones, inflammation and the metabolic syndrome: a population-based study," European Journal of Endocrinology, vol. 149, no. 6, pp. 601-608, 2003.

[23] J.-P. Després, B. Lamarche, P. Mauriège et al., "Hyperinsulinemia as an independent risk factor for ischemic heart disease," The New England Journal of Medicine, vol. 334, no. 15, pp. 952957, 1996.

[24] G. B. Phillips, T. Jing, and S. B. Heymsfield, "Relationships in men of sex hormones, insulin, adiposity, and risk factors for myocardial infarction," Metabolism, vol. 52, no. 6, pp. 784-790, 2003.

[25] E. C. Tsai, A. M. Matsumoto, W. Y. Fujimoto, and E. J. Boyko, "Association of bioavailable, free, and total testosterone with insulin resistance: influence of sex hormone-binding globulin and body fat," Diabetes Care, vol. 27, no. 4, pp. 861-868, 2004.

[26] R. K. Stellato, H. A. Feldman, O. Hamdy, E. S. Horton, and J. B. Mckinlay, "Testosterone, sex hormone-binding globulin, and the development of type 2 diabetes in middle-aged men: prospective results from the Massachusetts Male Aging Study," Diabetes Care, vol. 23, no. 4, pp. 490-494, 2000.

[27] E. L. Ding, Y. Song, V. S. Malik, and S. Liu, "Sex differences of endogenous sex hormones and risk of type 2 diabetes: a systematic review and meta-analysis," Journal of the American Medical Association, vol. 295, no. 11, pp. 1288-1299, 2006.

[28] H.-Y. Lin, Q. Xu, S. Yeh, R.-S. Wang, J. D. Sparks, and C. Chang, "Insulin and leptin resistance with hyperleptinemia in mice lacking androgen receptor," Diabetes, vol. 54, no. 6, pp. 1717$1725,2005$.

[29] D. Kapoor, C. J. Malkin, K. S. Channer, and T. H. Jones, "Androgens, insulin resistance and vascular disease in men," Clinical Endocrinology, vol. 63, no. 3, pp. 239-250, 2005.

[30] S. Bhasin, G. R. Cunningham, F. J. Hayes et al., "Testosterone therapy in adult men with androgen deficiency syndromes: an endocrine society clinical practice guideline," Journal of Clinical Endocrinology and Metabolism, vol. 91, no. 6, pp. 1995-2010, 2006.

[31] M. Rabijewski, M. Kubuj, and S. Zgliczynski, “The efficacy and safety of testosterone replacement therapy in elderly men with hypogonadism," Polish Journal of Endocrinology, vol. 3, pp. 293300, 2003.

[32] D. Kapoor, E. Goodwin, K. S. Channer, and T. H. Jones, “Testosterone replacement therapy improves insulin resistance, glycaemic control, visceral adiposity and hypercholesterolaemia in hypogonadal men with type 2 diabetes," European Journal of Endocrinology, vol. 154, no. 6, pp. 899-906, 2006.

[33] M. A. Boyanov, Z. Boneva, and V. G. Christov, “Testosterone supplementation in men with type 2 diabetes, visceral obesity and partial androgen deficiency," The Aging Male, vol. 6, no. 1, pp. 1-7, 2003. 


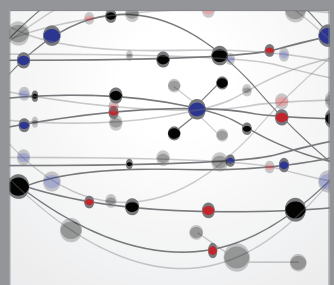

The Scientific World Journal
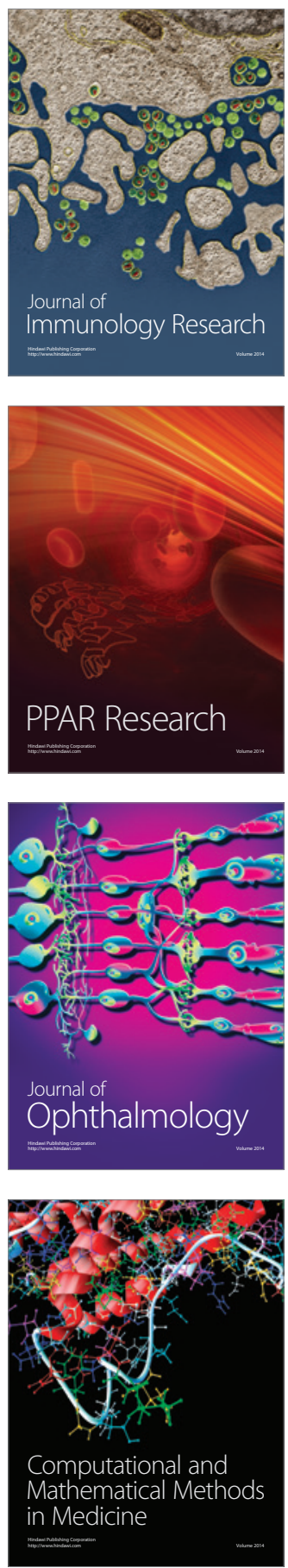

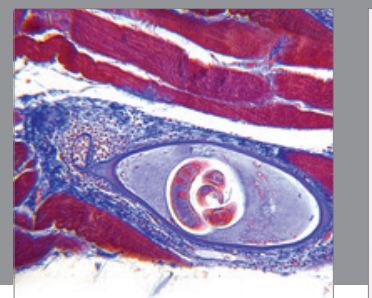

Gastroenterology

Research and Practice
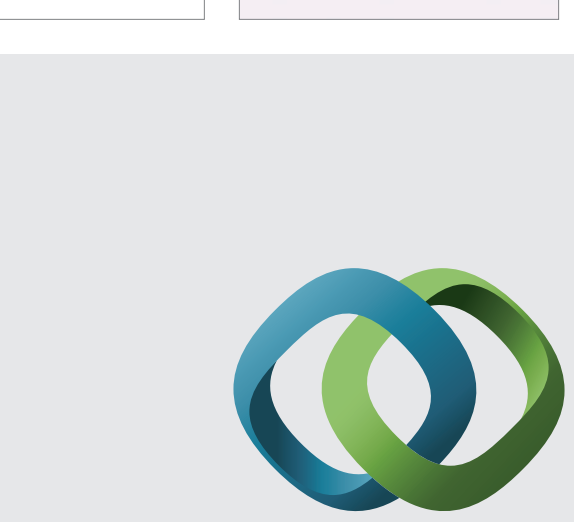

\section{Hindawi}

Submit your manuscripts at

http://www.hindawi.com
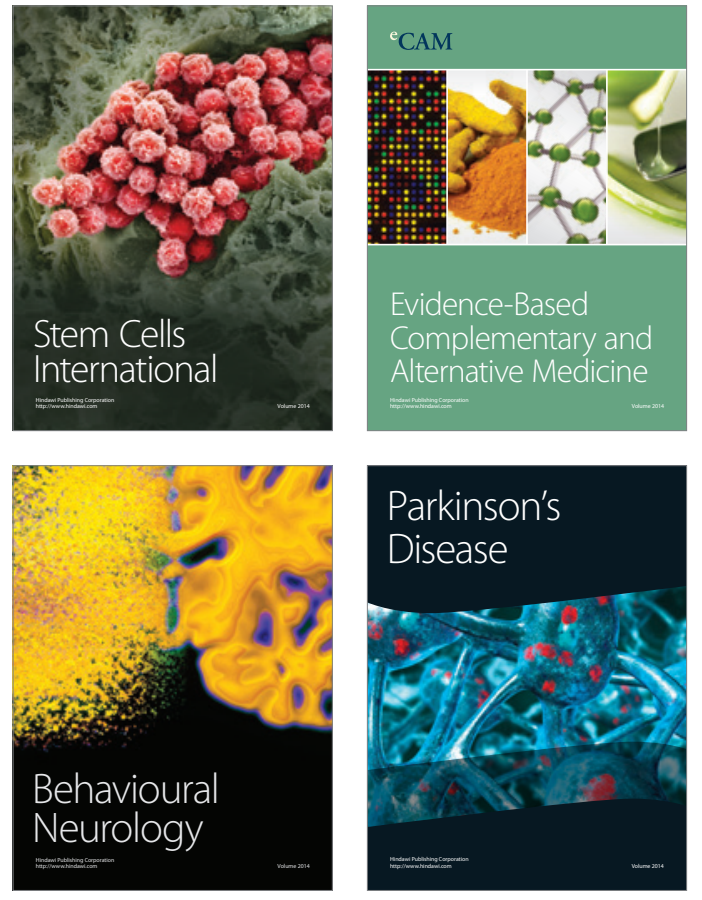
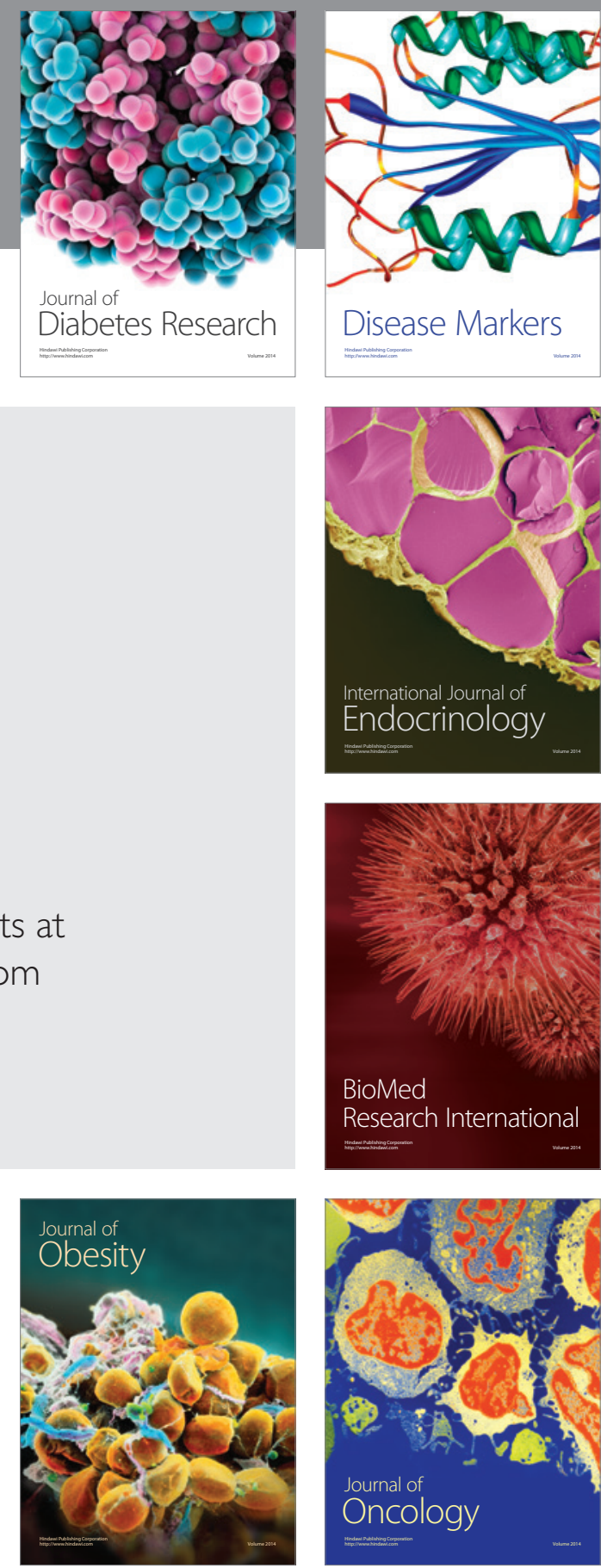

Disease Markers
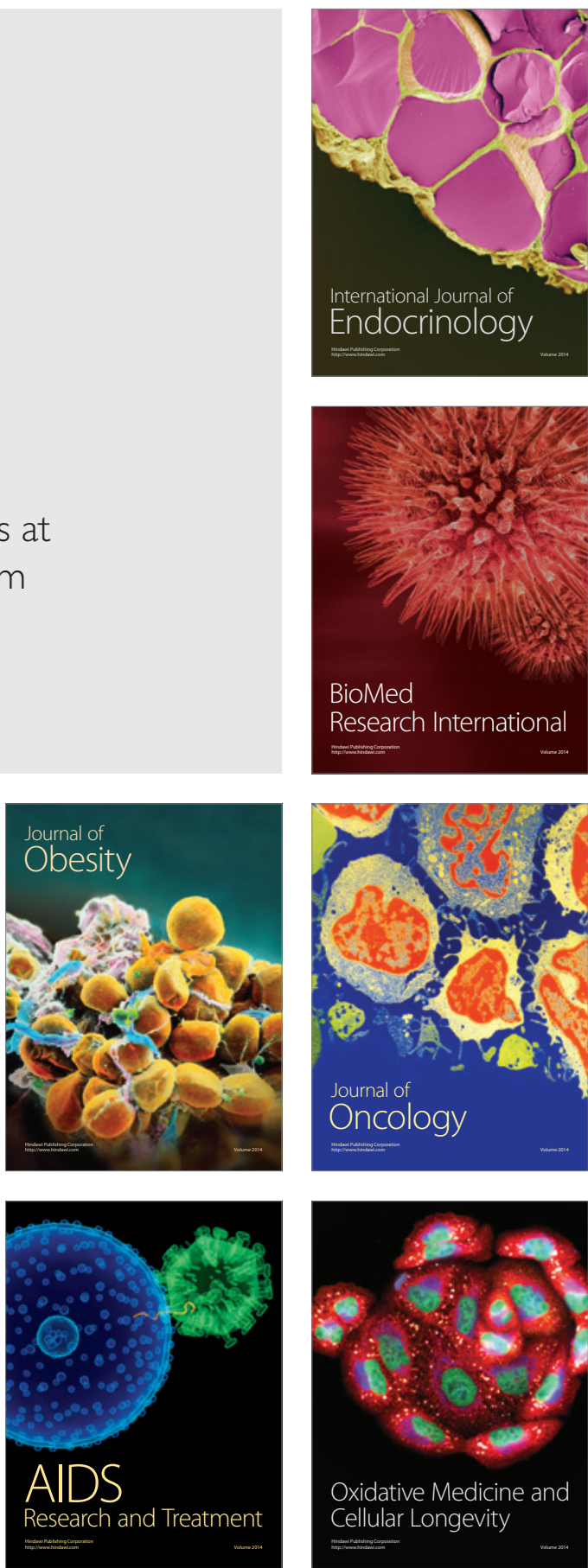